\title{
The Use of Seton as a Bridge to Definitive Ligation of the Intersphincteric Fistula Tract Procedure for Fistula-in-ano: A Systematic Review and Meta-analysis
}

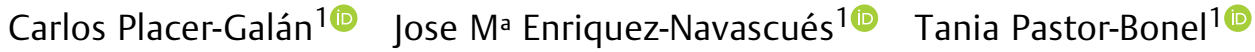 \\ Ignacio Aguirre-Allende ${ }^{10}$ Yolanda Saralegui-Ansorena ${ }^{10}$
}

${ }^{1}$ Colorectal Surgery Unit, Department of General and Digestive Surgery, Donostia University Hospital, Biodonostia (Gastrointestinal Diseases Group), San Sebastián, Spain

J Coloproctol 2021;41(3):308-315.
Address for correspondence Carlos Placer-Galán MD, PhD, EBSQc, Beguiristain Doktorea Pasealekua s/n, 20014, Donostia-San Sebastián, Spain (e-mail: carlos.placergalan@osakidetza.eus; carlos943313762@gmail.com).

\begin{abstract}
Keywords

- anal fistula

- seton

- LIFT

- intersphincteric
\end{abstract}

Background There is still controversy over the usefulness of seton placement prior to the ligation of the intersphincteric fistula tract (LIFT) surgery in the management of anal fistula.

Objective To evaluate the impact of preoperative seton placement on the outcomes of LIFT surgery for the management of fistula-in-ano.

Design systematic review and meta-analysis.

Data Sources A search was performed on the MEDLINE (PubMed), EMBASE, Scopus, Web of Science, Cochrane Library and Google Scholar databases.

Study Selection Original studies without language restriction reporting the primary healing rates with and without seton placement as a bridge to definitive LIFT surgery were included.

Intervention The intervention assessed was the LIFT with and without prior seton placement.

Main Outcome Measures The main outcome was defined as the primary healing rate with and without the use of seton as a bridge to definitive LIFT surgery.

Results Ten studies met the criteria for systematic review, all retrospective, with a pooled study population of 772 patients. There were no significant differences in the percentages of recurrence between patients with and without seton placement (odds ratio [OR] 1.02; $95 \%$ confidence interval $[\mathrm{Cl}]$ 0.73-1.43: $p=0.35$ ). The $\mathrm{I}^{2}$ value was $9 \%$, which shows the homogeneity of the results among the analyzed studies. The 10 included studies demonstrated a weighted average overall recurrence of $38 \%$ (interquartile range [IQR] received

August 28, 2020 accepted after revision January 15, 2021 published online July 19, 2021
DOI https://doi.org/ $10.1055 / \mathrm{s}-0041-1730039$ ISSN 2237-9363.

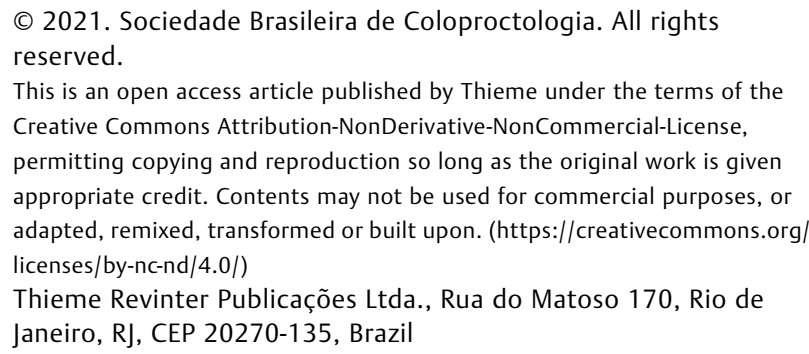
reserved.

This is an open access article published by Thieme under the terms of the Creative Commons Attribution-NonDerivative-NonCommercial-License, permitting copying and reproduction so long as the original work is given appropriate credit. Contents may not be used for commercial purposes, or adapted, remixed, transformed or built upon. (https://creativecommons.org/ licenses/by-nc-nd/4.0/)

Thieme Revinter Publicações Ltda., Rua do Matoso 170, Rio de Janeiro, RJ, CEP 20270-135, Brazil 
27-42.7\%), recurrence with the use of seton was $40 \%$ (IQR 26.6-51.2\%), and without its use, the recurrence rate was 51.3\% (IQR 31.3-51.3\%)

Limitations The levels of evidence found in the available literature were relatively fair, as indicated after qualitative evaluation using the Newcastle-Ottawa scale and the Attitude Heading Reference System (AHRS) evidence levels.

Conclusions Our meta-analysis suggests that the placement of seton as a bridge treatment prior to LIFT surgery does not significantly improve long-term anal fistula healing outcomes. Ligation of the intersphincteric fistula tract surgery can be performed safely and effectively with no previous seton placement.

International prospective register of systematic reviews-PROSPERO registration number: CDR42020149173.

\section{Introduction}

The aim of surgery for anal fistula is to eradicate local septic foci and promote healing of the fistula tract while preserving adequate anal continence. The treatment of complex anal fistula, considered as those not solved with a simple fistulotomy, still represents a major surgical challenge. Several surgical techniques have been described, albeit the vast majority associate fair-moderate healing rates.

In 2007, Rojanasakul described a new sphincter-preserving technique, ligation of the intersphincteric fistula tract (LIFT), ${ }^{1}$ modifying a classical surgical approach, the intersphincteric via, previously described in $1993 .^{2}$ The procedure is aimed at the cryptoglandular source of infection within the intersphincteric space.

The LIFT procedure has gained popularity in the last decade for its low-complexity, easy-to-learn technique and high definitive healing rate reliably exceeding $70 \%$, with little impact on anal continence. ${ }^{3-5}$ In addition, approximately one third of recurrences occur in the form of an intersphincteric fistula, which represents a downstage in complexity, transforming the initial challenging anal fistula surgery into a second manageable intervention. ${ }^{6}$

The LIFT technique is based on the dissection and ligation of the fistulous tract in the intersphincteric plane, for which consistent tissues and the absence of abscesses in this space are necessary. For this reason, some authors have recommended the placement of a seton prior to the LIFT procedure as a bridge therapy, with the intention of increasing fibrosis and the consistency of the fistulous tract, in addition to removing collections within the intersphincteric space. ${ }^{7,8}$

In the absence of randomized studies on the usefulness of a seton as a bridge to the definitive LIFT procedure in the treatment of complex anal fistula, we performed a systematic review of the published literature with the aim of answering the following specific question according to the problem, intervention, and comparison (PICO) framework: compared with patients who undergo a direct LIFT procedure for fistula-in-ano, do patients who undergo seton placement as a bridge to a deferred LIFT procedure have a better success rate?

\section{Methods}

A systematic review of the literature was performed following the Meta-analyses Of Observational Studies in Epidemiology (MOOSE) recommendations ${ }^{9}$ (Appendix A).

\section{Data Sources and Search Strategy}

A systematic search of standard electronic databases, including MEDLINE (PubMed), EMBASE, Web of Science, Cochrane Library and Google Scholar, was conducted for pertinent studies. In addition, the bibliographic references from selected studies were examined as a further search tool to find additional articles. Articles in all languages were considered for inclusion. A combination of MeSH terms and keywords was used to identify the target studies: LIFT OR ligation of intersphincteric fistula tract AND seton OR sedal AND anal fistula OR fistula-in-ano. The last search was performed on December 15, 2019.

\section{Eligibility Criteria}

Four reviewers (C. P. G., I. A. A., T. P. B., and Y. S. A.) independently screened the literature according to the inclusion and exclusion criteria. The defined inclusion criteria for full review included: 1) studies analyzing LIFT procedure, including patients with preoperative seton placement, and reporting outcomes on healing rate and recurrence 2 ) definitions of fistula definitive healing and treatment failure were specified in the study. According to the Preferred Reporting Items for Systematic Reviews and Meta-Analyses (PRISMA) guidelines, the predetermined exclusion criteria were: 1) study population smaller than 20 patients; 2) patients with anal fistula and Crohn disease; 3) modified LIFT procedures (BIO-LIFT, LIFT with anal flap, etc.); and 4) follow-up of less than 3 months. Discordant views were managed by review of original sources and discussion.

\section{Data Extraction}

We developed a data abstraction tool to capture the following data from each study: the names of the authors, title of the study, journal in which the study was published, country and publication date, study design, sample size, age and gender of the patients, follow-up time, percentage of 
recurrence and/or cure with and without seton use. Several authors were contacted and required to supply additional information for completion of data quantitative analysis. ${ }^{10,11}$ A proportion of authors were contacted but no response was obtained (Appendix B).

\section{Quality and risk of bias assessment in individual studies}

Each study was independently appraised by two investigators (I. A. A. and T. P. B.) using the Newcastle-Ottawa Scale $(\mathrm{NOS})^{12}$ for non-randomized studies. We performed the evaluations according to the three main items of study population selection, comparability and "assessment of outcomes. A study can be awarded a maximum of four stars for selection, two stars for comparability and three stars for outcome categories. The studies were grouped in terms of good quality, weak quality, and poor quality, according to the Agency for Health Research and Quality (AHRQ). ${ }^{13}$ If discrepancies were present, a consensus was reached by soliciting the help of a third author (C. P. G.).

\section{Data synthesis and statistical analysis}

Statistical analysis was performed with Review Manager (RevMan) v. 5.3 (Copenhagen: The Nordic Cochrane Center, Copenhagen Denmark). The odds ratios (ORs) were calculated from the original data. Values were expressed with a $95 \%$ confidence interval ( $\mathrm{CI})$. Heterogeneity among the included studies was qualitatively evaluated using chi-squared test based on the $Q$ test. A $p$-value $<0.05$ showed that there was no significant heterogeneity between the studies. The level of
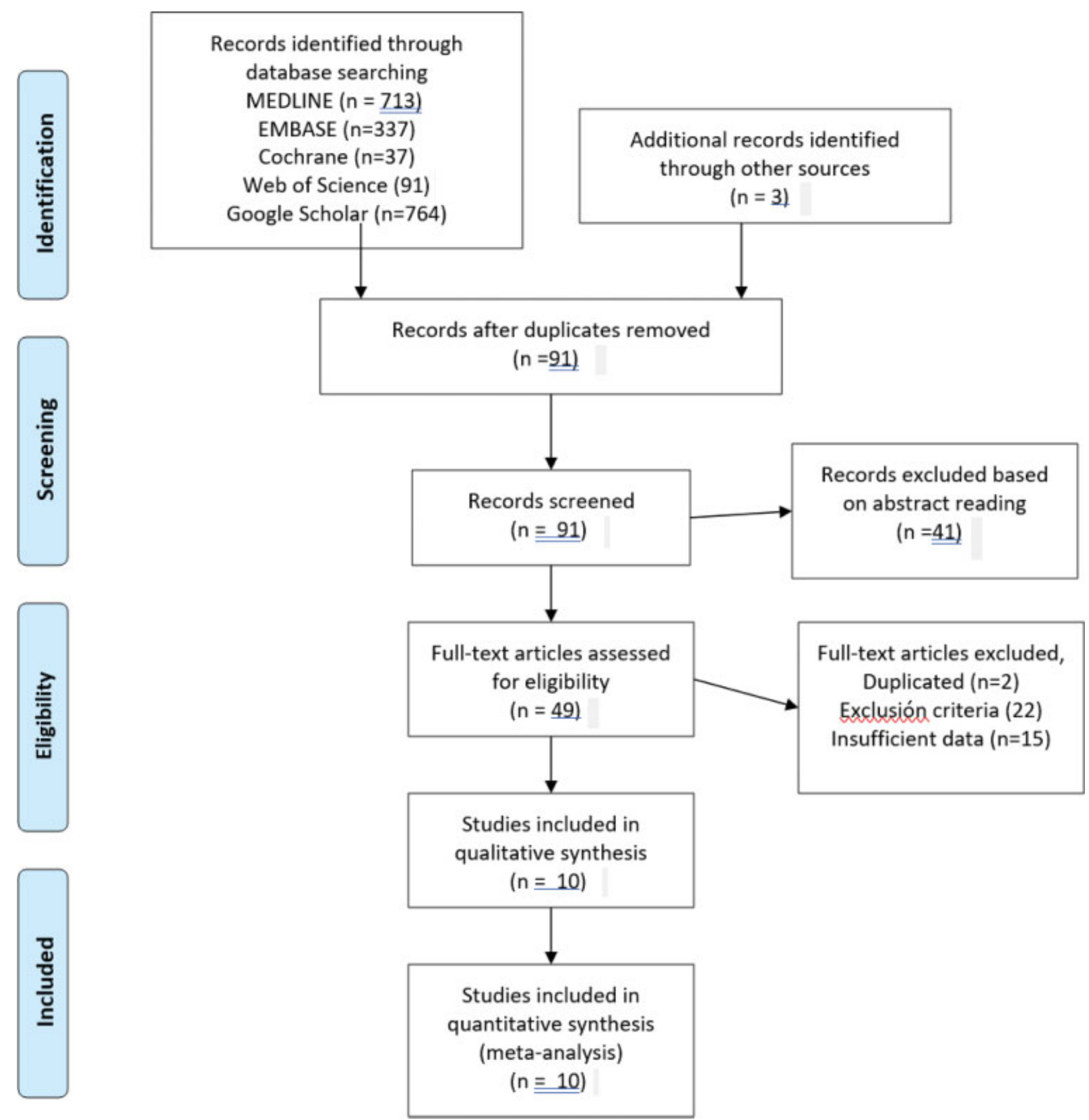

Fig. 1 Preferred Reporting Items for Systematic Reviews and Meta-Analyses Flow chart of the study selection. 
heterogeneity between the studies was calculated using the $\mathrm{I}^{2}$ statistic. An $\mathrm{I}^{2}<30 \%$ was considered to define low heterogeneity. Given the homogeneity of the included data, according to $\mathrm{I}^{2}$ test, the Mantel-Haenszel $(\mathrm{M}-\mathrm{H})$ method and the fixed-effects model were used for the quantitative analysis of the dichotomous variables. In addition, a sensitivity analysis was performed by clustering the studies according to the number of patients included and according to the NOS quality. The presence of publication bias was assessed using a funnel plot and the Begg and Egger tests.

\section{Results}

A systematic search of the literature was conducted from the date of description and publication of the LIFT surgery in March 2007 until December 2019. After review of the title and abstract, 49 articles were fully assessed for eligibility, and, finally, 10 studies, representing a total study population of 772 patients, were included for qualitative and quantitative analysis (- Fig. 1). ${ }^{6,10,11,14-20}$ The median age of the included patients was 44 years, and the female/male ratio was $23 \% / 77 \%$.
Most of the excluded studies had a small sample size $(<20$ patients), an absence of differential or stratified outcomes data between those in whom a seton was placed prior to LIFT procedure and of those who did not. A small number of studies that included mixed modified LIFT techniques (Bio-LIFT, associated flaps, etc.) or also included patients with anal fistula in Crohn disease. All the included studies were retrospective, such as cohort studies or case series, and comprehended patients treated between 2007 and 2016. Half of the included studies were from the USA. The median number of patients per study was 44 (R.I. 35-76). The median follow-up was greater than 1 year in all studies except in 2, both reporting a median follow-up time of more than 3 months. ${ }^{16,18}$ The majority of the included patients were diagnosed with trans-sphincteric fistulas, although some cases of recto-vaginal and posterior horseshoe fistulas were also considered (-Tables $\mathbf{1}$ and $\mathbf{2}$ ). All papers contained a definition of the complete fistula healing and treatment failure criteria. However, few studies assessed the potential impact on continence impairment or complications related to the use of setons.

The qualitative assessment of the included studies in the analysis displayed a weak-quality level according to the NOS

Table 1 Characteristics of the included studies and patients

\begin{tabular}{|c|c|c|c|c|c|c|c|c|c|c|c|}
\hline Author & Country & Year & Study design & Center(s) & Duration & Pacients & Age & $\begin{array}{l}\text { Gender } \\
(\mathrm{F} / \mathrm{M})\end{array}$ & $\begin{array}{l}\text { Follow-up } \\
\text { (months) }\end{array}$ & NOS & AHRQ \\
\hline Espin & Spain & 2011 & Retrospective & Single center & $?$ & 29 & $49(26-83)$ & $16 / 13$ & $1826-83)$ & 4 & Fair \\
\hline Wallin & USA & 2012 & Retrospectivee & Multicenter & $2007-2011$ & 93 & $43(21-76)$ & $36 / 57$ & $19(44-55)$ & 6 & Fair \\
\hline Liu & USA & 2013 & Retrospective & Single center & $2008-2011$ & 38 & 42 & $10 / 28$ & $26(3-44)$ & 3 & Poor \\
\hline Wang & USA & 2013 & Retrospective & Single center & $2011-2012$ & 71 & $41(18-71)$ & $16 / 55$ & $4(2-13)$ & 5 & Fair \\
\hline Ye & China & 2014 & Retrospective & Multicenter & $2012-2013$ & 41 & $45(17-59)$ & $15 / 28$ & $15(12-24)$ & 4 & Fair \\
\hline Sileri & Italy & 2014 & Retrospective & Multicenter & $2010-2012$ & 26 & $41(30-65)$ & $10 / 16$ & $20(16-24)$ & 6 & Fair \\
\hline Hall & USA & 2014 & Retrospective & Multicéntrico & $2011-2013$ & 43 & $45(31-59)$ & $? / ?$ & 3 & 3 & Poor \\
\hline Placer & Spain & 2017 & Retrospective & Single center & $2008-2016$ & 55 & $46(34-61)$ & $24 / 31$ & $32(6-51)$ & 7 & Good \\
\hline Sugrue & USA & 2017 & Retrospective & Multicenter & $2005-2015$ & 241 & $46(18-78)$ & $? / ?$ & $9(1-125)$ & 7 & Good \\
\hline Vander M. & Netherlands & 2019 & Retrospective & Single center & $2013-2015$ & 45 & $40(24-67)$ & $28 / 17$ & $12(6-24)$ & 5 & Fair \\
\hline
\end{tabular}

Abbreviations: AHRQ, Agency for Health Research and Quality; NOS, Newcastle-Ottawa scale.

Table 2 Outcome of the LIFT procedure in the studies reviewed

\begin{tabular}{|l|l|l|l|l|l|l|l|}
\hline Autor & $\begin{array}{l}\text { Patients } \\
(\mathrm{N})\end{array}$ & Fistula class & $\begin{array}{l}\text { Recurrence } \\
\mathrm{N}(\%)\end{array}$ & $\begin{array}{l}\text { Seton/ } \\
\text { No seton }\end{array}$ & $\begin{array}{l}\text { Recurrence } \\
\text { with seton N (\%) }\end{array}$ & $\begin{array}{l}\text { Recurrence } \\
\text { without } \\
\text { seton } \mathbf{n}(\%)\end{array}$ & $\begin{array}{l}\text { Complications } \\
\text { Seton/No Seton }\end{array}$ \\
\hline Espin & 29 & Transsphincteric & $10(35)$ & $24 / 5$ & $8(33.3)$ & $2(40)$ & $? / ?$ \\
\hline Wallin & 93 & $?$ & $56(60)$ & $70 / 23$ & $44(63)$ & $12(52)$ & $? / ?$ \\
\hline Liu & 38 & $?$ & $15(38)$ & $29 / 9$ & $11(38)$ & $4(44)$ & $? / ?$ \\
\hline Wang & 71 & $?$ & $9(12.7)$ & $18 / 53$ & $3(16.6)$ & $6(11.3)$ & $1 / 1$ \\
\hline Ye & 41 & Transsphincteric & $11(27)$ & $4 / 37$ & $0(0 \%)$ & $11(26.8)$ & $0 / 0$ \\
\hline Sileri & 26 & Trans/RV/horseshoe & $7(27)$ & $5 / 21$ & $2(40)$ & $5(24)$ & $? / ?$ \\
\hline Hall & 43 & Trans/RV/horseshoe & $9(21)$ & $30 / 13$ & $8(26.6)$ & $1(7.7)$ & 9 \\
\hline Placer & 55 & Trans/Supra & $16(29)$ & $12 / 43$ & $2(16.6)$ & $14(32.5)$ & $0 / 0$ \\
\hline Sugrue & 241 & Transsphincteric & $103(42.7)$ & $148 / 93$ & $64(51.2)$ & $39(51.3)$ & $? / ?$ \\
\hline Vander & 45 & Trans/ano-vaginal & $27(60)$ & $32 / 13$ & $19(59.3)$ & $8(61.5)$ & $0 / 0$ \\
\hline
\end{tabular}




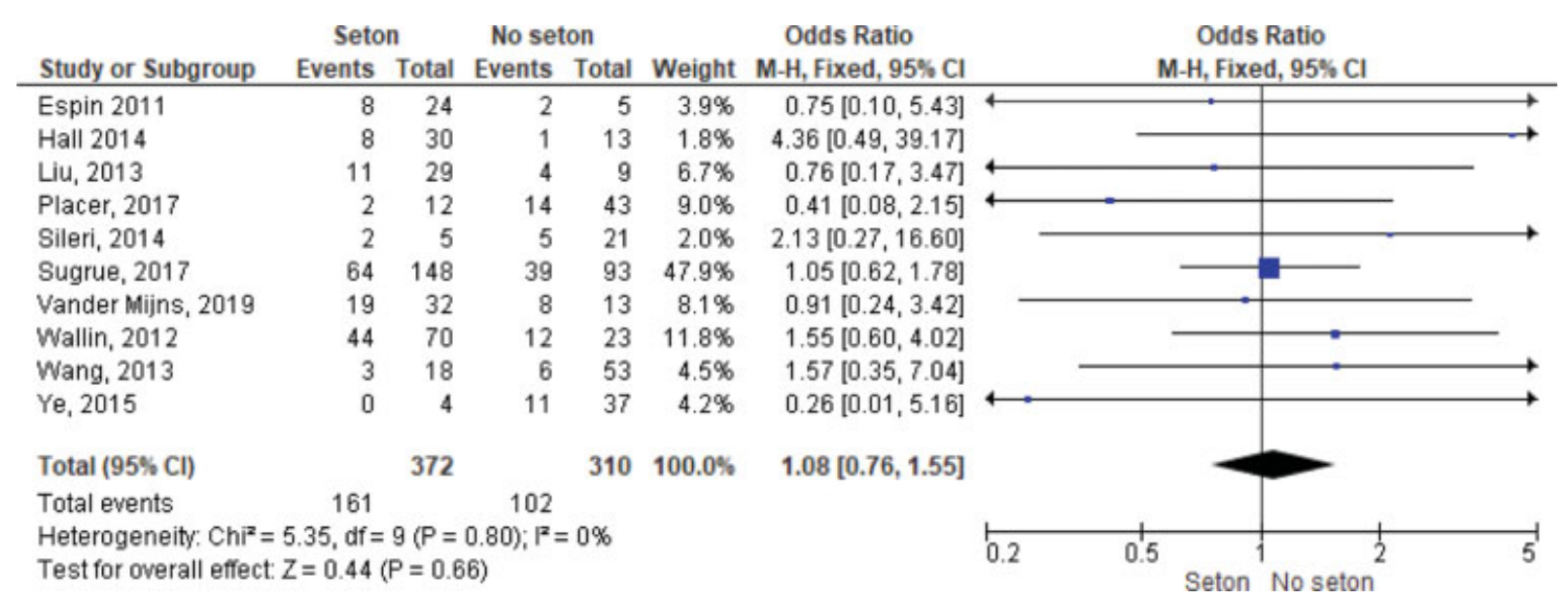

Fig. 2 Forest plot for success with and without seton.

tool. Furthermore, the AHRQ classification tool showed two studies of good quality, two of poor quality, and eight of weak quality (Appendix C).

There were no significant differences in fistula recurrence rate between patients with and without seton placement before LIFT surgery (OR $1.02 ; 95 \%$ CI $0.73-1.43$ : $p=0.35$ ). The $\mathrm{I}^{2}$ value was $9 \%$, expressing high homogeneity of results among the selected studies. The quantitative analysis of the included studies showed a weighted average of overall recurrence of $38 \%$ (IQR 27-42.7\%). Overall recurrence rate in patients with previous seton placement was 40\% (IQR 26.6-51.2\%), in contrast to a 51.3\% (IQR 31.3$51.3 \%)$ recurrence rate in patients without prior seton use (-Fig. 2).

A sensitivity analysis was performed according to the number of patients included in each selected study (more or less than 50 patients) and also stratified by the NOS quality rating of analyzed studies. None of the compared subgroups showed advantages with the use of a seton in terms of the healing or recurrence rates (- Figures $\mathbf{3}, \mathbf{b}, \mathbf{c}, \mathbf{d}$ ). Publication bias was also assessed and reported using a funnel plot (-Fig. 4). In addition, Begg $(Z=1.1657 ; p=0.441)$ and the Egger $(t=-0.8014, p=0.441)$ tests were also performed for publication bias evaluation. All three tests showed an absence of significant bias, which is consistent with the high homogeneity found in the results of the included studies.

\section{Discussion}

The present systematic review and meta-analysis shows that prior placement of a seton as a bridge therapy to perform a definitive LIFT surgery for fistula-in-ano does not seem to improve the long-term outcomes of the technique. However, the inherent risk of bias of the included non-randomized studies should be considered when interpreting the results.

The proposal of addressing the intersphincteric space as a surgical approach for anal fistula surgery is already established as a result of the cryptoglandular infection theory defining the source of most anal fistulas. In 1993, Matos et al. published a series of 13 cases ( 8 high trans-sphincter and 5 suprasphincteric fistulas) in which 7 out of 13 cases experienced complete healing of fistula (54\%) after a median follow-up of 22 months (4-33). ${ }^{2}$ Despite not having great diffusion, in 2007, Rojanasakul resumed the idea and described a modified surgical technique, nowadays known as the LIFT procedure. ${ }^{1}$

To perform effective ligation of the intersphincteric tract, the existence of a mature fistula tract and the absence of secondary tracks or active suppurative local septic foci are mandatory. Thus, to obtain a more fibrous and consistent tract, some authors have suggested the placement and maintenance of a non-cutting seton for a few weeks prior to the definitive ligation of the fistulous tract. ${ }^{15,21-23}$ However, some studies question the idea of the seton favoring the development of a more consistent fistulous tract path. ${ }^{7,24}$ Furthermore, in the original series of Rojanasakul, with more than 250 patients, the use of a previous seton was not mentioned. ${ }^{25}$

The effect produced by a loose seton on the orifices and the tract of a fistula-in-ano has been poorly documented. Mitalas et al. did not found a relationship between the placement of a seton and the presence or development of epithelium in the fistulous tract. ${ }^{26}$ Moreover, curettage of the fistulous tract is considered a routine gesture before the placement of a seton in fistula surgery, with the elimination of the epithelium within the fistulous tract being one of the main purposes. However, the need to eliminate nests of epithelial cells is still debated. ${ }^{27}$ In addition, some studies have questioned this maneuver because of the risk of creating additional secondary fistula tracts or false passage into the anal canal, ${ }^{17}$ and because of the possible enlargement of internal fistulous orifices. ${ }^{28}$ Moreover, only 2 studies have stratified their results according to the use of a seton, with sample sizes of 71 and 43 patients, and found a similar percentage of recurrence with and without seton use. ${ }^{16,18}$

Most of the studies included in the present meta-analysis showed that the placement of a seton prior to the LIFT procedure had no effect on the outcome in terms of definitive 
a

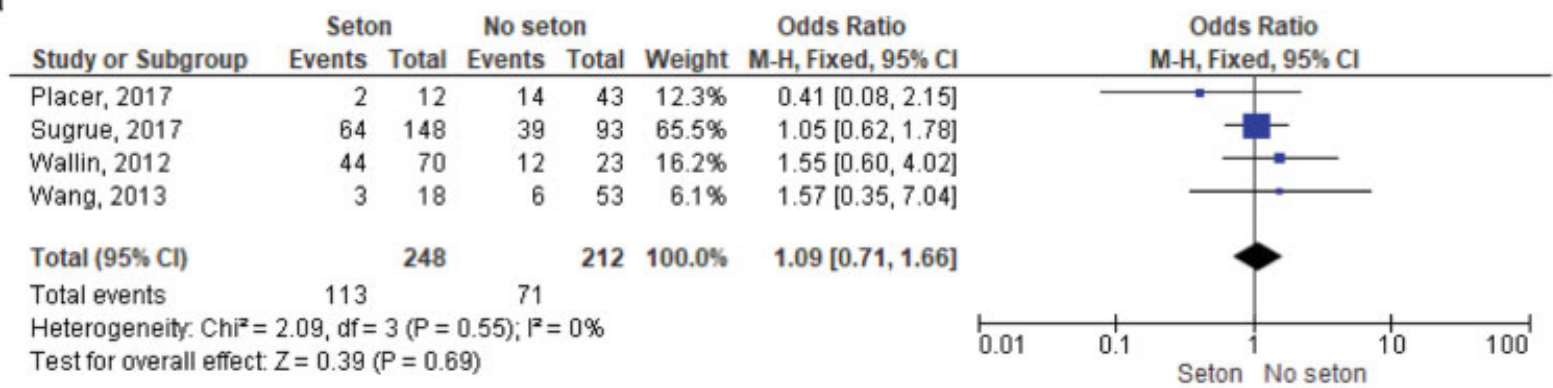

b

\begin{tabular}{|c|c|c|c|c|c|c|c|c|c|c|}
\hline \multirow[b]{2}{*}{ Study or Subgroup } & \multicolumn{2}{|c|}{ Seton } & \multicolumn{2}{|c|}{ No seton } & \multicolumn{2}{|r|}{ Odds Ratio } & \multirow{2}{*}{\multicolumn{4}{|c|}{$\begin{array}{c}\text { Odds Ratio } \\
\text { M-H, Fixed, } 95 \% \mathrm{Cl}\end{array}$}} \\
\hline & Events & Total & Events & Total & Weight & M-H, Fixed, $95 \% \mathrm{Cl}$ & & & & \\
\hline Espin 2011 & 8 & 24 & 2 & 5 & $14.5 \%$ & $0.75[0.10,5.43]$ & - & & & \\
\hline Hall 2014 & 8 & 30 & 1 & 13 & $6.7 \%$ & $4.36[0.49,39.17]$ & & & & \\
\hline Liu, 2013 & 11 & 29 & 4 & 9 & $24.9 \%$ & $0.76[0.17,3.47]$ & $\rightarrow-$ & & & \\
\hline Sileri, 2014 & 2 & 5 & 5 & 21 & $7.6 \%$ & $2.13[0.27,16.60]$ & & & & \\
\hline Sileri, 2014 & 0 & 0 & 0 & 0 & & Not estimable & & & & \\
\hline Vander Mijns, 2019 & 19 & 32 & 8 & 13 & $30.4 \%$ & $0.91[0.24,3.42]$ & & & & \\
\hline Ye, 2015 & 0 & 4 & 11 & 37 & $15.8 \%$ & $0.26[0.01,5.16]$ & & & & \\
\hline Total $(95 \% \mathrm{Cl})$ & & 124 & & 98 & $100.0 \%$ & $1.07[0.53,2.16]$ & & & & \\
\hline Total events & 48 & & 31 & & & & & & & \\
\hline $\begin{array}{l}\text { Heterogeneity. } \mathrm{Chr}^{2}= \\
\text { Test for overall effect }\end{array}$ & $\begin{array}{l}3.25, d f= \\
Z=0.20\end{array}$ & $\begin{array}{l}5(P= \\
P=0.8\end{array}$ & $\begin{array}{l}0.66) ; P^{2}= \\
34)\end{array}$ & $0 \%$ & & & $\begin{array}{cc}0.01 & 0.1 \\
& \text { Favours [experi }\end{array}$ & 1 Favours [c & $\begin{array}{l}10 \\
\text { ontrol] }\end{array}$ & 100 \\
\hline
\end{tabular}

C

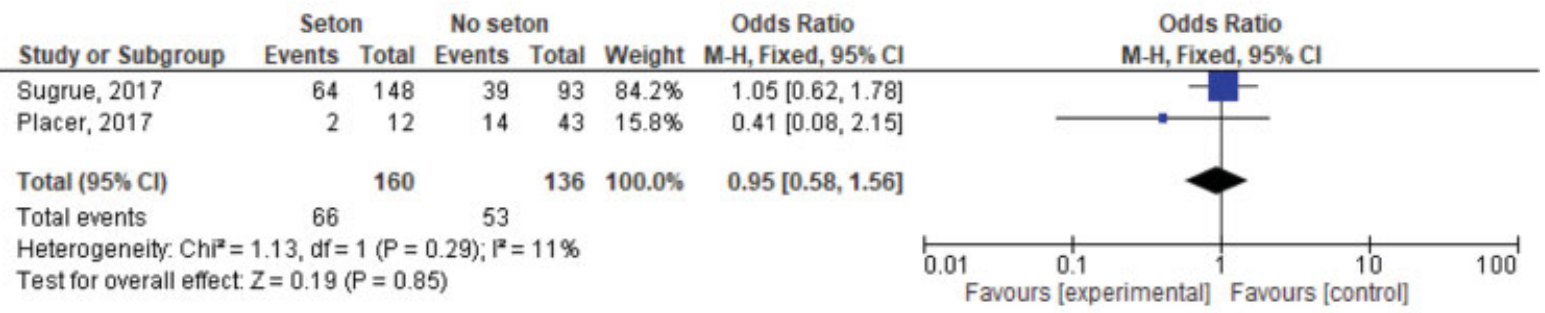

d

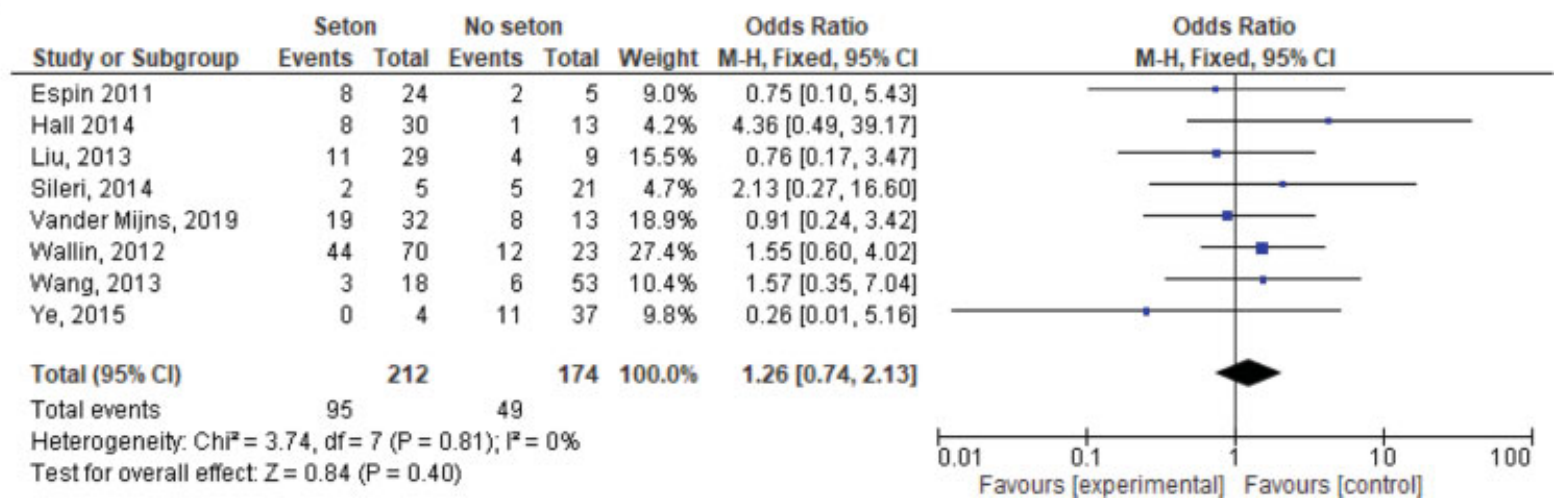

Fig. 3 Analysis of sensitivity forest plot. (a) Forest plot for success according to number of patients (> 50 patients). (b) Forest plot for success according to number of patients (<50 patients). (c) Forest plot for success according to the Newcastle-Ottawa scale (good quality). (d) Forest plot for success according to the Newcastle-Ottawa scale (fair/poor quality).

healing or recurrence rates of anal fistula. For many years, the use of seton prior to LIFT surgery for fistula-in-ano has been a highly controversial subject. Sileri et al. attributed worse results to the use of setons because of the possibility of creating false tracts. ${ }^{17}$ Tan et al. also reported worse results in their retrospective study including 24 patients who had a seton before the definitive LIFT procedure. The authors argued that the healing of the inflammatory process around 


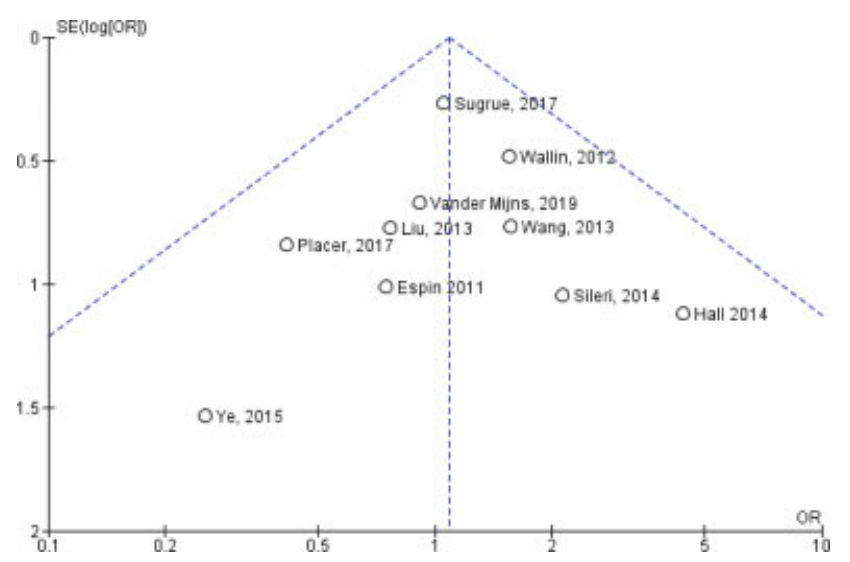

Fig. 4 Funnel plot to assess publication bias.

the seton could obliterate the intersphincteric space, making subsequent dissection difficult and increasing the risk of anal canal mucosa damage. ${ }^{29}$ However, the same authors recommended the use of setons for selected cases, such as in high transsphincteric or suprasphincteric fistulas, due to the downstaging effect of the fistulous tracts. In contrast, Ye et al. recommended removing the seton before LIFT surgery to maintain the integrity of the internal fistulous orifice. ${ }^{19}$ Likewise, additional authors have supported the use of a seton as bridge treatment for definitive LIFT procedure, considering the potential downstaging and shortening of the fistulous tract, whose length could constitute a risk factor for recurrence. ${ }^{15,30}$ Aboulian et al. also recommended the use of a seton as a bridge to surgery, but only in the presence of a septic foci (i.e., abscess) and for a period of less than 8 weeks. $^{31}$

The main weakness of the present study is the absence of randomized controlled trials (RCTs) in the literature; therefore, the available studies were not designed to analyze the specific role of seton placement in the LIFT procedure. Furthermore, since these were not randomized studies, the fact that some LIFT procedures would have to be abandoned due to the impossibility of making a good ligation of the fistulous tract due to the lack of consistent tissue cannot be ruled out. Thus, these cases might not have been included in the analyzed studies.

However, the exhaustive bibliographic search and the fulfilment of defined inclusion and exclusion criteria allowed to obtain a highly representative study population with homogeneous results that yielded, in the absence of RCTs, consistent and repeated conclusions. In the absence of prospective, randomized studies, the current study represents the first meta-analysis addressing the specific role of seton in LIFT surgery.

\section{Conclusion}

Seton as a bridge treatment prior to LIFT surgery does not significantly improve long-term anal fistula healing outcomes. Ligation of the intersphincteric fistula tract surgery can be performed safely and effectively with no previous seton placement. However, the inherent bias of non-randomized retrospective studies should be considered for results interpretation. Thus, additional prospective studies are required to clarify the role of previous seton placement in LIFT surgery for fistula-in-ano.

\section{Conflict of Interests}

The authors declare that there is no conflict of interests.

\section{References}

1 Rojanasakul A, Pattanaarun J, Sahakitrungruang C, Tantiphlachiva K. Total anal sphincter saving technique for fistula-in ano: The ligation of intersphincteric fistula tract. J Med Assoc Thai 2007; 90:581-586

2 Matos D, Lunniss PJ, Phillips RKS. Total sphincter conservation in high fistula in ano: results of a new approach. Br J Surg 1993; 80:802-804

3 Emile SH, Khan SM, Adejumo A, Koroye O. Ligation of intersphincteric fistula tract (LIFT) in treatment of anal fistula: An updated systematic review, meta-analysis, and meta-regression of the predictors of failure. Surgery 2020;167(02):484-492

4 Hong KD, Kang S, Kalaskar S, Wexner SD. Ligation of intersphincteric fistula tract (LIFT) to treat anal fistula: systematic review and meta-analysis. Tech Coloproctol 2014;18:685-691

5 Gendia AM. Abd-erRazik MA, Hanna HH. Ligation of the intersphincteric fistula tract procedure and its modifications. J Coloproctol (Rio J) 2018;38:324-336

6 Placer Galán C, Lopes C, Múgica JA, Saralegui Y, Borda N, Enriquez Navascués JM. Patterns of recurrence/persistence of criptoglandular anal fistula after the LIFT procedure. Long-term observatinal study. Cir Esp 2017;95:385-390

7 Yassin NA, Hammond TH, Lunniss PJ, Phillips RKS. Ligation of the intersphincteric fistula tract in the management of anal fistula. A systematic review. Colorectal Dis 2013;15:527-535

8 Zirak-Schmidt S, Perdawood SK. Management of anal fistula by ligation of the intersphincteric fistula tract-a systematic review. Dan Med J 2014;61:A4977

9 Stroup DF, Berlin JA, Morton SC, et al. Meta-analysis of observational studies in epidemiology: a proposal for reporting. Metaanalysis Of Observational Studies in Epidemiology (MOOSE) group. JAMA 2000;283:2008-2012

10 Espin E, Lozoya R, Vallribera F, Jimenez LM, Marti M, Sánchez M. LIF (Ligation of intersphincteric fistula tract): long-term results. Colorectal Dis 2011;13(Suppl 6):47

11 Sugrue J, Mantgilla N, Abcarian A, et al. Sphincter-sparing anal fistula repair: Are we getting better? Dis Colon Rectum 2017; 60:1071-1077

12 Wells GA, Shea B, O'Connell D, et al. The Newcastle-Ottawa Scale (NOS) for assessing the quality if nonrandomized studies in meta-analyses. Ottawa: Ottawa Hospital Research Institute; 2013

13 Penson DF, Krishnaswami S, Jules A. Newcastle-Ottawa Quality Assessment form for Cohort studies. Ottawa: Ottawa Hospital Research Institute; 2012

14 Wallin UG, Mellgren AF, Madoff RD, Goldberg SM. Does ligation of the intersphincteric fistula tract raise the bar in fistula surgery. Dis Colon Rectum 2012;55:1173-1178

15 Liu WI, Aboulian A, Kaji AH, Kumar RR. Long-term results of ligation of intersphincteric fistula tract (LIFT) for fistula-in-ano. Dis Colon Rectum 2013;56:343-347

16 Wang QM, Chong HY, Wexcner SD, Hong KD, Maron DJ, Silva GD. Seton placement prior to lift: does it affect the outcome? Colorectal Dis 2013;15(Suppl 1):56

17 Sileri P, Giarratano G, Franceschilli L, et al. Ligation of the intersphincteric fistula tract (LIFT): A minimally invasive procedure for complex anal fistula: Two-year results of a prospective multicentric study. Surg Innov 2014;2:476-480 
18 Hall JF, Bordeianou L, Hyman N, et al. Outcomes after operations for anal fistula: results of a prospective, multicenter, regional study. Dis Colon Rectum 2014;57:1304-1308

19 Ye F, Tang $\mathrm{CH}$, Wang D, Zheng S. Early experience with the modificated approach of ligation of the intersphincteric fistula tract for high transsphincteric fistula. World J Surg 2015; 39:1059-1065

20 Vander Mijnsbrugge GJH, Felt-Bersma RJF, Ho DKF, Molenaar CBH. Perianal fistulas and the lift procedure: results, predictive factors for success and long-term results with subsequent treatment. Tech Coloproctol 2019;23:639-647

21 Moreno N, Readi A, Melkonian E, Capona R, Martinez M. Ligadura interesfinteriana del trayecto fistuloso (LIFT) como alternativa de tratamiento a una fístula perianal compleja. Rev Chil Cir 2019; 71:42-46

22 Lynn P, Carrano FM, Grieco M, Carter J, Grucela A, Bernstein M. Ligation of the intersphincteric fistula tract: are there any factors associated with persistent/recurrence? Dis Colon Rectum 2019; 62:e339-e340

23 Mushaya CH, Bartlett L, Schultze B, Ho YH. Ligation of intersphincteric fistula tract compared with advancement flap for complex anorectal fistulas requering inictial seton drainage. Am J Surg 2012;204:283-289

24 Stellingwerf ME, van Pragg EM, Tozer PJ, Bemelman WA, Buskens CJ. Systematic review and meta-analysis of endorectal advance- ment flap and ligation of the intersphincteric fistula tract for cryptoglandular and Crohn's high perianal fistulas. Br J Surg 2019; 3:231-241

25 Malakorn S, Sammour T, Khomvilai S, et al. Ligation of intersphincteric fistula tract for fistula in ano: Lessons learned from a decade of experience. Dis Colon Rectum 2017;60:1065-1070

26 Mitalas LE, van Onkelen RS, Monkhorst K, Zimmerman DD, Gosselink MP, Schouten WR. Identification of epitheliazation in high transsphincteric fistulas. Tech Coloproctol 2012; 16:113-117

27 van Koperen PJ, ten Kate FJ, Bemelman WA, Slors JF. Histological identification of epithelium in perianal fistulae: a prospective study. Colorectal Dis 2009;12:891-895

28 Koh SZ, Tsang CB. The LIFT procedure. Sem Colon Rectum. 2014; 25:190-199

29 Tan KK, Alsuwaigh R, Tan AM, et al. To LIFT or to flap? Which surgery to perform following seton insertion for high anal fistula?. Dis Colon Rectum 2012;55:1273-1277

30 Schultze B, Ho YH. Management of compolex anorectal fistulas with seton drainage plus partial fistulotomy and subsequent ligation of intersphincteric fistula tract (LIFT). Tech Coloproctol 2015;19:89-95

31 Aboulian A, Kaji AH, Kumar RR. Early result of ligation of the intersphincteric fistula tract for fistula-in-ano. Dis Colon Rectum 2011;54(03):289-292 